Rev. Adm. Saúde Vol. 17, Nº6, Jan. - Mar. 2017

EDITORIAL

\title{
Gestão em Saúde
}

\author{
Haino Burmester ${ }^{1}$ \\ 1. Vice-Presidente da ABRAMPAS
}

Na década de 1970 a Organização Pan-Americana da Saúde propôs como estratégia para melhoria do setor hospitalar nas Américas que os países desenvolvessem programas de formação de recursos humanos para a área conjugando esforços dos melhores hospitais da região com as melhores escolas de administração de empresas. A racionalidade por trás desta estratégia era que juntando estes recursos se cobririam as necessidades de treinamento dos quadros para administrar os hospitais latino-americanos e se esperava, por extensão, também os sistemas de saúde onde estes hospitais estavam inseridos. Em alguns países esta estratégia chegou a funcionar bem, enquanto que em outros não chegou nem a passar da fase de projeto. No Brasil, o PROAHSA em São Paulo, criado dentro desta proposta, continua até hoje formando quadros para o sistema de saúde brasileiro tendo-o feito por meio de diferentes atividades que já qualificaram mais de 5 mil pessoas espalhadas pelo país afora. O PROAHSA é o Programa Avançado de Administração Hospitalar e Sistemas de Saúde mantido pelo Hospital das Clínicas da Faculdade de Medicina da Universidade de São Paulo e pela Escola de Administração de Empresas de São Paulo da Fundação Getúlio Vargas.

No Brasil sempre se estabeleceu uma dicotomia entre o que se chama de medicina preventiva, social, comunitária, "sanitarismo" ou saúde pública e o que representa administração ou gestão dos serviços de saúde. Já seja por interesses de reserva de mercado de trabalho; por razões ideológicas; ou por pura incompreensão do que seja gestão de serviços de saúde, sempre pairou no ar uma desconfiança de que "administrar" era um verbo inadequado para ser conjugado relativamente à saúde. Dizia-se que administrar era algo relacionado com empresas privadas que não tinham nada a ver com saúde. Que não se podia pensar em eficiência quando se falava em saúde porque esta era um bem maior que não podia ser quantificado em termos de dinheiro, produtividade ou racionalidade. Todos os recursos deveriam sempre estar disponíveis para a saúde "porque saúde não tem preço!"

Hoje sabemos muito bem que a saúde de um indivíduo não tem preço, mas pode custar muito caro e que os recursos, individuais ou coletivos, são sempre escassos para fazer frente às despesas que a recuperação desta saúde possa requerer. Portanto, é preciso que os agentes envolvidos nesta equação, de fornecer saúde ao indivíduo ou ao grupo de indivíduos, tenham bem presente a 
importância de preocupar- se com os custos deste fornecimento, para que ele possa ser estendido ao maior número possível de pessoas que dele necessitem. E que quando se fala em medicina preventiva, social, comunitária ou saúde pública se esteja falando também em aperfeiçoar o uso dos recursos escassos disponíveis para a saúde, de modo que um número maior de pessoas tenha acesso aos serviços de maneira equitativa, integral e universal para fazer frente aos agravos de maior parte da população. E que, portanto, se está falando de administrar bem os recursos disponíveis de maneira que eles sejam usados eficiente, eficaz e efetivamente. Que a função do gestor neste contexto (seja ele chamado de administrador de saúde, sanitarista, "preventivista", médico social ou comunitário) é fazer com que os recursos que Ihe forem colocados à disposição deem o maior retorno possível em termos de benefícios à saúde da população. A isto se chama: administrar.

As faculdades de saúde pública das universidades mais importantes do mundo há muito já se convenceram destas verdades e passaram a incorporar em seus currículos conteúdos de disciplinas que preparam seus alunos para fazer frente aos desafios que a moderna gestão dos serviços de saúde impõe. Estes desafios demandam gestores que saibam enfrentar questões ligadas à: liderança organizacional; estatística; epidemiologia; sociologia; antropologia; demografia; mercadologia; contabilidade e finanças; planejamento estratégico e operativo; gestão de pessoas; gestão de processos e outras. Questões que estão relacionadas com a gestão de recursos humanos, financeiros, materiais e organizacionais que serão colocados nas mãos dos gestores e que estes deverão saber o que fazer com eles; ter uma proposta gerencial concreta (e não apenas reacional) quanto ao uso destes recursos e prestar contas de suas ações a quem de direito público ou privado. Ter um modelo de gestão e saber executá-lo. Não há escapatória; estes são os fatos puros e simples como estão colocados sobre a mesa da realidade. O futuro dirá quem fez sua lição de casa e quem não a fez; não haverá como fugir do julgamento da história cuja retrospectiva costuma ser implacável.

Isto não significa, entretanto, que o papel do gestor ou administrador está limitado pelos muros da instituição ou do hospital em que trabalha. A sua ação junto à comunidade, com as comissões de saúde, com os grupos que reivindicam mais recursos para o setor, nas Associações Profissionais e de classe, é parte indissociável de seu trabalho.

Assim, com a transformação da Sociedade Médica Brasileira de Administração em Saúde (fundada em 27/11/76) na Associação Brasileira de Medicina Preventiva e Administração em Saúde (ABRAMPAS), o que se pretende é exatamente sinalizar a necessidade desta aproximação de conteúdos e integralização do conhecimento para fazer frente aos desafios da saúde no Brasil. Espera-se que a junção simbólica dos dois conceitos no nome da ABRAMPAS sinalize aos observadores a necessidade do entendimento desta dimensão abrangente da administração em saúde. Ela pretende contribuir com o setor saúde mediante a disseminação destes conceitos, muito mais do que, necessariamente, congregar os gestores de saúde do país e a sua mensagem é no sentido de estimular a reflexão sobre as reais necessidades e prioridades na área da saúde. A ABRAMPAS, conforme seu estatuto, propõe-se a 
promover o desenvolvimento da Medicina Preventiva e da Administração em Saúde, além do intercâmbio científico, cultural e social entre os profissionais médicos que atuam nestas áreas em todo o território nacional. Além destas finalidades genéricas a Associação também se propõe a:

a) patrocinar estudos sobre a atividade na forma de cursos, simpósios, conferências, investigação científica e atividades correlatas;

b) promover o aperfeiçoamento dos profissionais dedicados à Medicina Preventiva e à Administração em Saúde;

c) defender os interesses dos profissionais médicos que trabalham na área de Medicina Preventiva e Administração em Saúde.

Estes objetivos específicos se materializam na disseminação de uma forma concreta de se fazer administração, abordando os aspectos principais da ação de um gestor de saúde: a liderança; o planejamento; a relação com clientes; a relação com a sociedade; a gestão das informações; a gestão das pessoas; a gestão dos processos; e a análise dos resultados. Estas ações serão necessárias seja na administração de um hospital de pequeno, médio ou grande porte; da capital ou das pequenas comunidades do interior; públicos ou privados; de centros de saúde, unidades básicas, AMA's ou AME's; UPA's; planos e operadoras de saúde; unidades do núcleo central de uma secretaria municipal, estadual ou mesmo do Ministério da Saúde.

Recebido em: 28/11/2016

Aceito e publicado em: 30/11/2016

Endereço para correspondência: Dr. Haino Burmester. Avenida Brigadeiro Luis

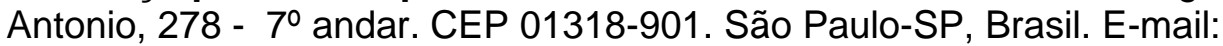
cqh@apm.org.br

Conflito de Interesses: Os autores declaram não haver conflito de interesses.

(C) This is an Open Access article distributed under the terms of the Creative Commons Attribution License, which permits unrestricted use, distribution, and reproduction in any medium, provided the original work is properly cited. 